\title{
Indicadores de gestión del GAD Municipalidad de Patate
}

\section{Una perspectiva financiera}

El presente artículo caracteriza el comportamiento de los principales indicadores relacionadas con la gestión del GAD Municipal de Patate, se cuenta con información resumen de ingresos y gastos de las cédulas presupuestarias de los años 2010 al 2014, proporcionado por la Dirección Financiera de la institución.

Es preciso describir que la gestión de los Gobiernos Autónomos Descentralizados (GAD), se rige al Código Orgánico de Organización Territorial, Autonomía y Descentralización (COOTAD) y al Código Orgánico de Planificación y Finanzas Públicas (COPFP), en este último, el Art. 34 en su parte pertinente describe que "los presupuestos de los gobiernos autónomos descentralizados y sus empresas públicas se sujetarán a sus propios planes, en el marco del Plan Nacional de Desarrollo y sin menoscabo de sus competencias y autonomías". (COPFP., 2010: 15), por lo tanto las decisiones deben reflejar una organización articulada con una participación ciudadana activa.

\section{Ingresos}

En función de la ejecución presupuestaria, en el periodo de análisis el crecimiento promedio anual del total de ingresos es del 5,5\%, siendo el año 2010 un valor de USD 3'844.276,72 y en el 2014 de USD 4'720.042,20.

En el periodo de estudio 2010-2014, el crecimiento promedio anual de los grupos de ingreso más representativo es el de capital $(18,6 \%)$, seguido por los ingresos corrientes $(7,9 \%)$, se evidencia un decrecimiento del rubro de financiamiento $(9,5 \%)$.

Tabla 1: Resumen de ingresos del GAD Municipal de Patate, valores devengados en dólares. Periodo 2010-2014.

\begin{tabular}{|l|c|c|c|c|c|}
\hline \multicolumn{1}{|c|}{ Años } & 2010 & 2011 & 2012 & 2013 & 2014 \\
\hline Ingresolles & $\$ 822.380,15$ & $\$ 565.840,07$ & $\$ 584.008,17$ & $\$ 550.168,72$ & $\$ 910.837,50$ \\
\hline Impuestos corrientes & $\$ 250.331,10$ & $\$ 190.141,18$ & $\$ 252.954,06$ & $\$ 236.139,97$ & $\$ 231.306,52$ \\
\hline Tasas y contribuciones & $\$ 50.649,76$ & $\$ 69.324,70$ & $\$ 60.777,50$ & $\$ 70.861,16$ & $\$ 358.111,18$ \\
\hline Venta de bienes y servicios & $\$ 152.635,30$ & $\$ 140.729,12$ & $\$ 134.031,97$ & $\$ 148.295,45$ & $\$ 202.549,07$ \\
\hline Renta de inversiones y multas & $\$ 64.938,28$ & $\$ 65.259,81$ & $\$ 79.526,83$ & $\$ 66.946,72$ & $\$ 64.987,48$ \\
\hline $\begin{array}{l}\text { Transferencias y conaciones } \\
\text { corrientes }\end{array}$ & $\$ 289.257,19$ & $\$ 19.993,24$ & - & - & - \\
\hline Otros ingresos & $\$ 14.568,52$ & $\$ 80.392,02$ & $\$ 56.717,81$ & $\$ 27.925,42$ & $\$ 53.883,25$ \\
\hline Ingresos de capital & $\$ 1^{\prime} 636.897,56$ & $\$ 2^{\prime} 723.196,50$ & $\$ 2^{\prime} 860.103,74$ & $\$ 3^{\prime} 141.501,45$ & $\$ 2^{\prime} 933.204,08$ \\
\hline Venta de activos no financieros & $\$ 7.221,15$ & $\$ 12.866,01$ & $\$ 18.627,08$ & $\$ 15.847,56$ & $\$ 31.677,20$ \\
\hline Recuperación de inversiones & - & - & - & - & - \\
\hline $\begin{array}{l}\text { Transferencias y donaciones } \\
\text { de capital e inversión }\end{array}$ & $\$ 1^{\prime} 629.676,41$ & $\$ 2^{\prime} 710.330,49$ & $\$ 2^{\prime} 841.476,66$ & $\$ 3^{\prime} 125.653,89$ & $\$ 2^{\prime} 901.526,88$ \\
\hline Ingresos de financiamiento & $\$ 1^{\prime} 384.999,01$ & $\$ 1^{\prime} 173.458,29$ & $\$ 803.867,29$ & $\$ 845.850,15$ & $\$ 876.000,62$ \\
\hline Financiamiento público & $\$ 167.627,20$ & $\$ 230.084,01$ & $\$ 141.324,00$ & $\$ 36.267,45$ & - \\
\hline Saldos disponibles & $\$ 874.708,35$ & $\$ 375.895,41$ & $\$ 419.491,09$ & $\$ 723.457,35$ & $\$ 724.457,35$ \\
\hline Cuentas pendientes por cobrar & $\$ 342.663,46$ & $\$ 567.478,87$ & $\$ 243.052,20$ & $\$ 86.125,35$ & $\$ 151.543,27$ \\
\hline Ingreso Total & $\$ 3^{\prime} 844.276,72$ & $\$ 4^{\prime} 462.494,86$ & $\$ 4^{\prime} 247.979,20$ & $\$ 4^{\prime} 537.520,32$ & $\$ 4^{\prime} 720.042,20$ \\
\hline
\end{tabular}

En el periodo 2010-2014, el grupo representativo en promedio son los ingresos de capital con $61 \%$ del total de ingresos, según el clasificador presupuestario de ingresos y gastos del sector público, estos "provienen de la venta de bienes de larga duración, de intangibles, de la recuperación de inversiones y de la recepción de fondos como transferencias o donaciones sin contraprestación, destinadas a la inversión en la formación bruta de capital. Su devengamiento produce contablemente modificaciones directas en la composición patrimonial del Estado" (Ministerio de Finanzas., 2014:35). Mientras que los de menos participación promedio son los de financiamiento con un $23,3 \%$ y corriente con el $15.7 \%$.

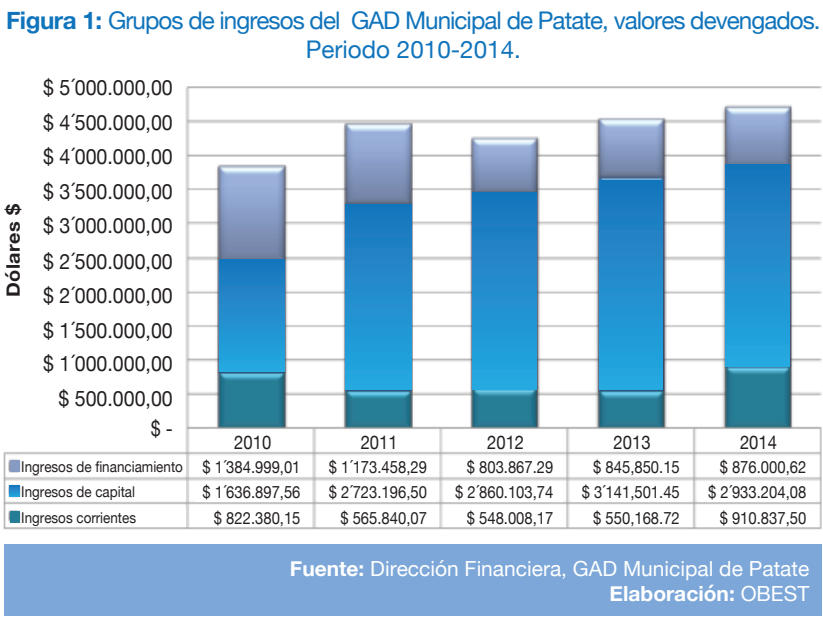

\section{Gastos}

Los gastos del GAD Municipal de Patate, en el año 2010 llegaron a USD 2'831.013,87, para el 2014 descendieron a USD 2'374.162,33, a pesar de esto, se evidencia un promedio al alza del 3,5\%. El promedio anual de incremento de los grupos de gasto, están los de capital $(126,2 \%)$ y a ritmo más bajo los corrientes $(9,9 \%)$ y de inversión $(0,9 \%)$.

Tabla 2: Resumen de gastos del GAD Municipal de Patate, valores devengados en dólares. Periodo 2010-2014.

\begin{tabular}{|c|c|c|c|c|c|}
\hline $\begin{array}{ll}\text { Detalles } & \text { Años } \\
\end{array}$ & 2010 & 2011 & 2012 & 2013 & 2014 \\
\hline Gastos corrientes & $\$ 509.048,92$ & $\$ 666.172,15$ & $\$ 742.224,12$ & $\$ 823.884,20$ & $\$ 819.912,58$ \\
\hline Gastos de personal & $\$ 357.694,91$ & $\$ 507.838,74$ & $\$ 582.260,73$ & $\$ 619.222,13$ & $\$ 618.408,90$ \\
\hline Bienes y Servicios de consumo & $\$ 99.576,42$ & $\$ 90.732,28$ & $\$ 91.066,62$ & $\$ 124.436,05$ & $\$ 128.106,45$ \\
\hline Gastos financieros & $\$ 24.456,21$ & $\$ 31.793,26$ & $\$ 28.352,51$ & $\$ 37.706,14$ & $\$ 15.218,28$ \\
\hline Otros gastos corrientes & $\$ 7.131,52$ & $\$ 3.904,93$ & $\$ 4.369,76$ & $\$ 5.556,53$ & $\$ 3.447,65$ \\
\hline $\begin{array}{l}\text { Transferencias y donaciones } \\
\text { corrientes }\end{array}$ & $\$ 20.189,86$ & $\$ 31.902,94$ & $\$ 36.174,50$ & $\$ 36.963,35$ & $\$ 54.731,30$ \\
\hline Gastos de Producción & - & & $\$ 8.260,00$ & $\$ 8.487,61$ & $\$ 11.918,93$ \\
\hline Bienes y Servicios de consumo & - & & $\$ 8.260,00$ & $\$ 8.487,61$ & $\$ 11.918,93$ \\
\hline Gastos de inversión & $\$ 1^{\prime} 776.958,43$ & $\$ 2 ' 753.819,83$ & $\$ 2^{\prime} 085.744,25$ & $\$ 2^{\prime} 390.188,12$ & $\$ 2^{\prime} 079.100,08$ \\
\hline $\begin{array}{l}\text { Gasto en personal para } \\
\text { inversión }\end{array}$ & $\$ 444.822,88$ & $\$ 476.687,38$ & $\$ 443.169,63$ & $\$ 463.798,25$ & $\$ 471.136,58$ \\
\hline $\begin{array}{l}\text { Bieness y servicios para } \\
\text { inversión }\end{array}$ & $\$ 415.355,17$ & $\$ 772.812,46$ & $\$ 671.699,31$ & $\$ 775.555,21$ & $\$ 853.863,30$ \\
\hline Obras públicas & $\$ 889.571,24$ & $\$ 1^{\prime} 363.426,12$ & $\$ 837.769,36$ & $\$ 1^{\prime} 011.445,75$ & $\$ 612.619,55$ \\
\hline Otros gastos de inversión & $\$ 10.287,89$ & $\$ 11.463,57$ & $\$ 15.461,45$ & $\$ 29.084,75$ & $\$ 25.511,60$ \\
\hline $\begin{array}{l}\text { Transferencias y donaciones } \\
\text { para inversión }\end{array}$ & $\$ 16.921,25$ & $\$ 129.430,30$ & $\$ 117.644,50$ & $\$ 110.304,16$ & $\$ 115.969,05$ \\
\hline Gastos capital & $\$ 329.331,64$ & $\$ 27.860,25$ & $\$ 239.448,28$ & $\$ 45.891,35$ & $\$ 35.684,91$ \\
\hline Bienes de larga duración & $\$ 329.331,64$ & $\$ 27.860,25$ & $\$ 239.448,28$ & $\$ 45.891,35$ & $\$ 35.684,91$ \\
\hline Gastos capital & $\$ 179.667,13$ & $\$ 201.271,70$ & $\$ 370.271,48$ & $\$ 122.288,06$ & $\$ 105.502,12$ \\
\hline Amortizaciones de la deuda & $\$ 179.667,13$ & $\$ 201.271,70$ & $\$ 239.448,28$ & $\$ 122.288,06$ & $\$ 104.216,05$ \\
\hline Pasivo circulante & & & $\$ 130.823,20$ & & $\$ 1.286,07$ \\
\hline Gastos capital & $\$ 2^{\prime} 795.006,12$ & $\$ 3^{\prime} 649.123,93$ & $\$ 3^{\prime} 445.948,13$ & $\$ 3^{\prime} 390.739,34$ & $\$ 3^{\prime} 052.118,62$ \\
\hline
\end{tabular}


En el periodo 2010-2014 el grupo más representativo es el de gastos de inversión con un promedio del 67,9\% del total de gastos que "son los recursos destinados al incremento patrimonial del Estado, mediante actividades operacionales de inversión, comprendido en programas sociales o proyectos institucionales de ejecución de obra pública. Están conformados por gastos en personal, bienes y servicios destinados a la inversión, obras públicas y transferencias de inversión" (Ministerio de Finanzas., 2014:73). Los de menos representatividad están los gastos corrientes con $21,8 \%$, la aplicación del financiamiento es $6 \%$, los de capital en $4,2 \%$ y los de producción $0.2 \%$.

Figura 2: Grupos de gastos del GAD Municipal de Patate, valores devengados. Periodo 2010-2014.

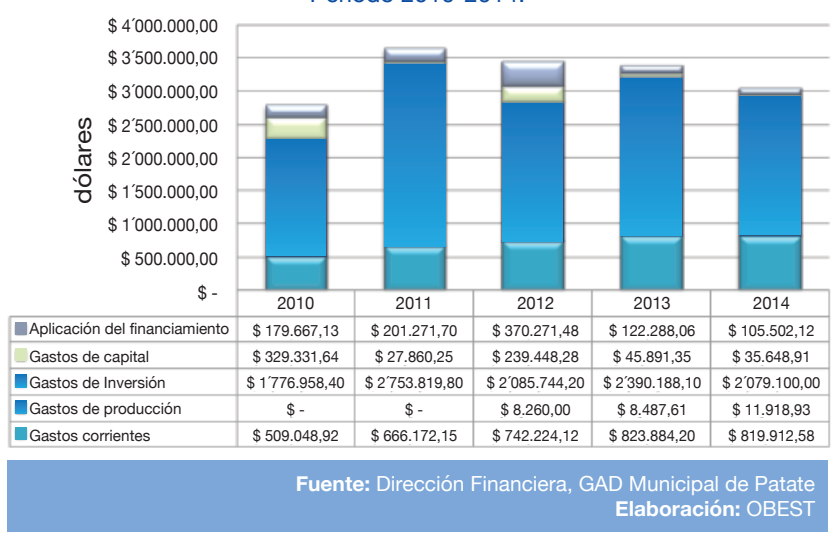

Indicadores de gestión

Como parte de las acciones tomadas por el GAD Municipal de Patate, en el periodo 2010-2014, se analizan nueve indicadores financieros que permiten describir el desempeño y resultados en términos económicos.

\section{Autonomía}

Se considera como autonomía a la participación de los ingresos propios sobre los ingresos totales, es decir, entre mayor sea este indicador es mejor porque demuestra la autonomía financiera que posee el gobierno seccional, la situación óptima es que supere el $80 \%$, sin embargo, en el periodo de análisis el promedio es 14,25\%, siendo el año 2014 con mayor capacidad de generación de recursos o autofinanciamiento llegando al 19,3\%, mientras que el año más bajo en relación al promedio fue 2013 con el 12,1\%.

Figura 3: Indicador de autonomía financiera del GAD Municipal de Patate. Periodo 2010-2014.

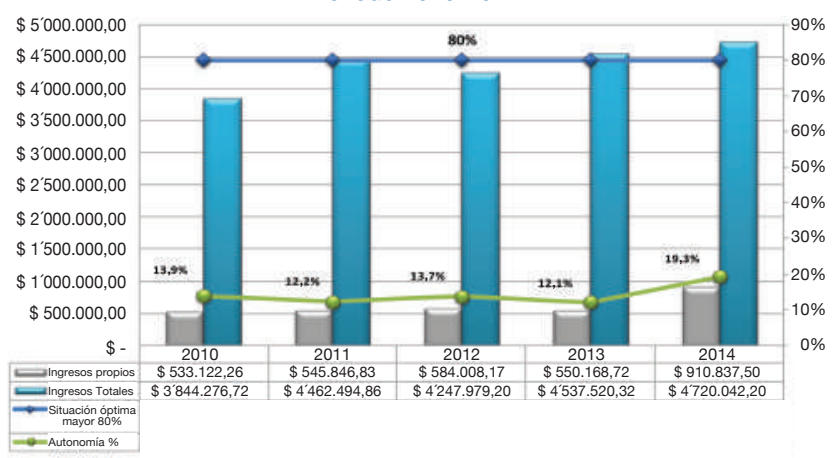

Fuente: Dirección Financiera, GAD Municipal de Patate Elaboración: OBEST

\section{Dependencia}

Es la relación que existe entre los ingresos por transferencias que realiza el gobierno central sobre los ingresos totales, mientras este valor sea menor, la gestión institucional se califica como positiva, la situación óptima es que llegue a ser menor que el $20 \%$, en el caso del GAD Municipal de Patate presenta un promedio de $61,67 \%$. En el periodo 2010-2014, el mejor año fue 2010 que registró el 49,92\% y el valor más alto se sitúa en el año 2013 con el 68,8\%.

Figura 4: Indicador de dependencia financiera del GAD Municipal de Patate. Periodo 2010-2014.

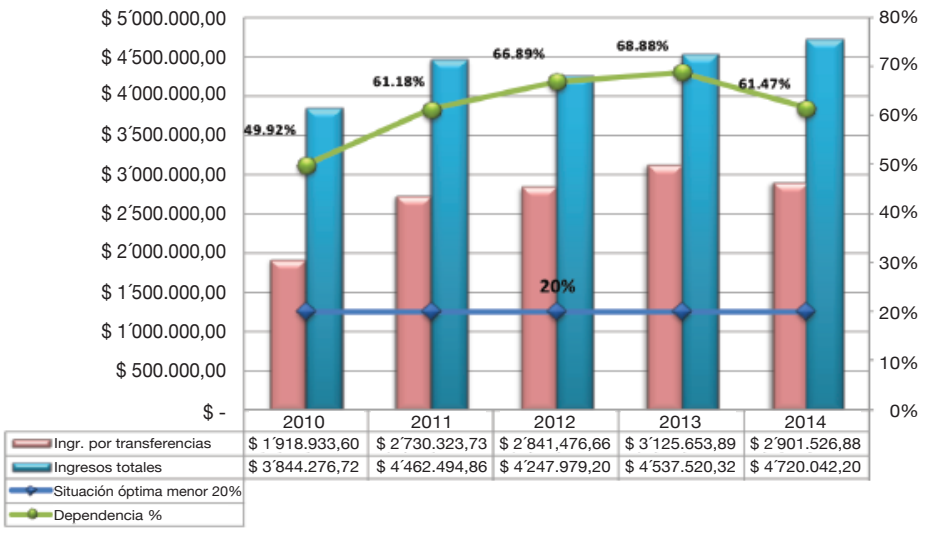

Fuente: Dirección Financiera, GAD Municipal de Patate Elaboración: OBEST

\section{Ahorro corriente}

Para evaluar la capacidad de endeudamiento del GAD Municipal de Patate, se realiza la diferencia del ingreso corriente frente al gasto corriente, la situación óptima es que el resultado sea positivo, en el periodo de análisis presenta valores negativos desde el año 2011 al 2013, por lo que en promedio es USD 25,601.47 negativo, y sólo en los años 2010 y 2014 presenta valores positivos (ver figura 5).

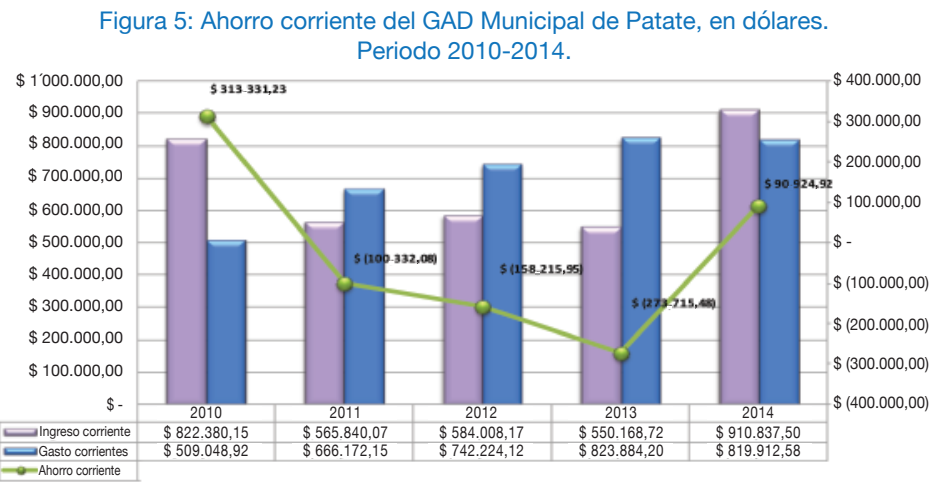

\section{Fuente: Dirección Financiera, GAD Municipal de Patate}

Elaboración: OBEST

\section{Solvencia}

Es la capacidad de cumplir con las obligaciones en el corto plazo o considerado en la manera qué el GAD Municipal de Patate financia sus actividades operativas, la meta de este indicador es que sea igual o mayor al 100\%, el promedio entre los años 2010-2014 es $100,61 \%$, lo que indica, que la utilización de los recursos son cubiertos por los gastos de capital o propician ahorro corriente. 
Figura 6: Solvencia financiera del GAD Municipal de Patate. Periodo 2010-2014

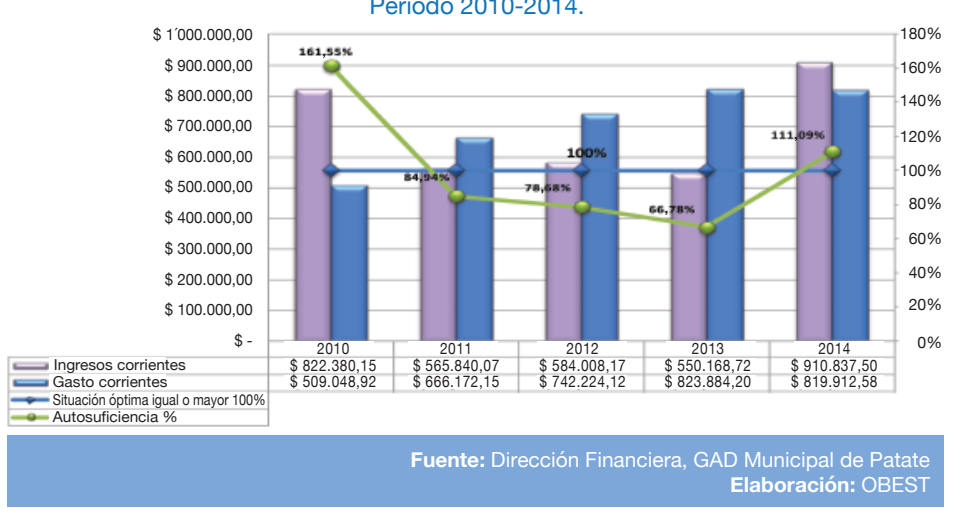

\section{Autosuficiencia}

Evalúa la capacidad de Financiamiento del GAD Municipal de Patate para hacer frente a los gastos operativos y de administración, la situación óptima es que sea mayor al 100\%, el promedio de los años de estudio es $88,64 \%$, siendo los años que cumple con la meta el 2010 y 2014.

Figura 7: Autosuficiencia financiera del GAD Municipal de Patate. Periodo 2010-2014.

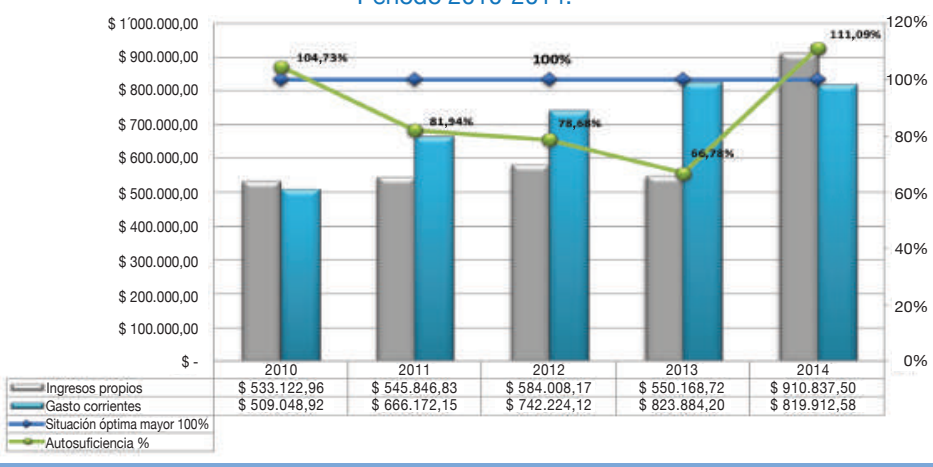

Fuente: Dirección Financiera, GAD Municipal de Patate Elaboración: OBEST

\section{Autosuficiencia mínima}

Si los resultados superan a la meta óptima que sea mayor al 100\%, significa que el GAD Municipal de Patate puede cubrir los gastos de remuneraciones con sus recursos propios, el promedio es $118,59 \%$, el año que presenta un valor inferior es el 2013 con el $88,85 \%$.

Figura 8: Autosuficiencia mínima del GAD Municipal de Patate. Periodo 2010-2014.

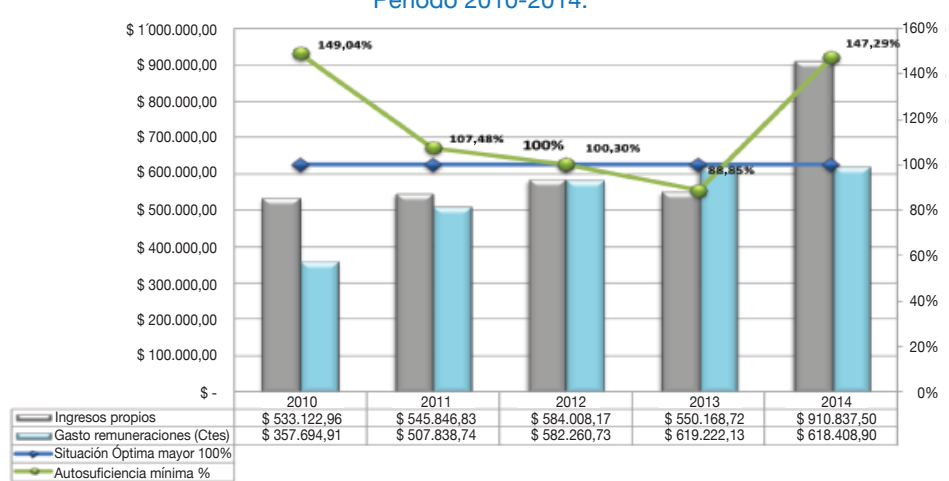

Fuente: Dirección Financiera, GAD Municipal de Patate

\section{Peso de la remuneración}

El efecto de las remuneraciones del GAD Municipal de Patate con relación al gasto corriente, se considera una situación óptima que sea menor al $60 \%$, el promedio en el periodo de análisis es $75,11 \%$, el año 2010 es el que más se acerca a la meta y el porcentaje más elevado es en el año 2012.

Figura 9: Efecto de las remuneraciones del GAD Municipal de Patate. Periodo 2010-2014.

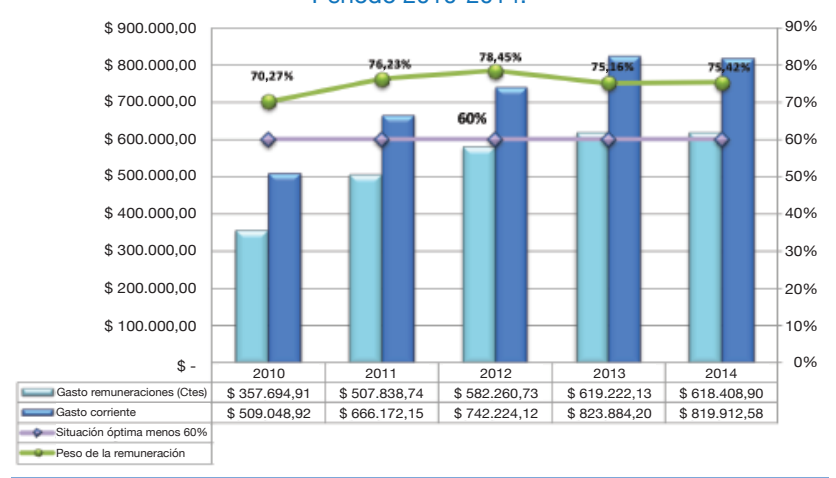

Fuente: Dirección Financiera, GAD Municipal de Patate Elaboración: OBEST

\section{Remuneración y presupuesto}

La relación es para describir en qué porcentaje las remuneraciones del GAD Municipal de Patate hace frente al presupuesto total, por cuanto el promedio de los años de análisis es del 30,62\%, siendo la situación óptima es que no sobrepase el $30 \%$, los porcentajes más altos se registran en los años 2013 y 2014, mientras que los años que llegan a la meta fueron del 2010 al 2012.

Figura 10: Remuneración y presupuesto del GAD Municipal de Patate. Periodo 2010-2014.

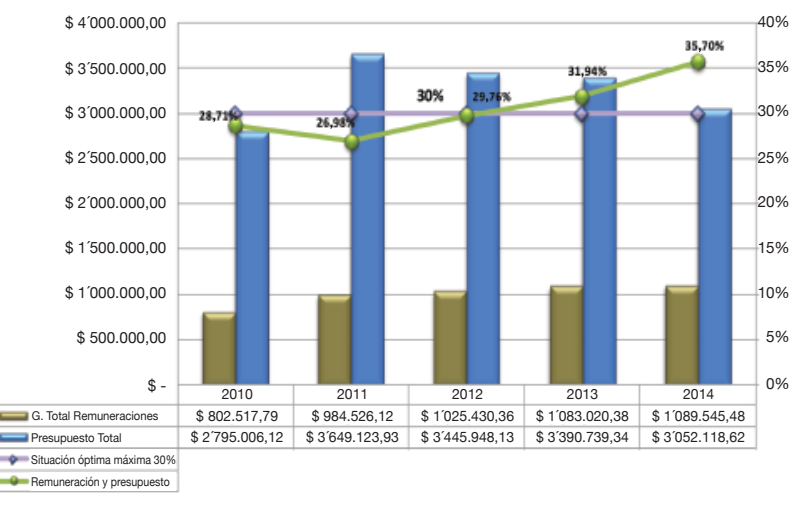

Fuente: Dirección Financiera, GAD Municipal de Patate Elaboración: OBEST

\section{Ingreso y egreso per-cápita}

El ingreso promedio propio por habitante que percibe el GAD Municipal de Patate es de USD 44,76 mientras que los egresos que realiza en inversiones per-cápita son de USD 159,38. 


\section{Ingreso y egreso per-cápita}

El ingreso promedio propio por habitante que percibe el GAD Municipal de Patate es de USD 44,76 mientras que los egresos que realiza en inversiones per-cápita son de USD 159,38 .

Figura 11: Ingreso y egreso per cápita del GAD Municipal de Patate. Periodo 2010-2014

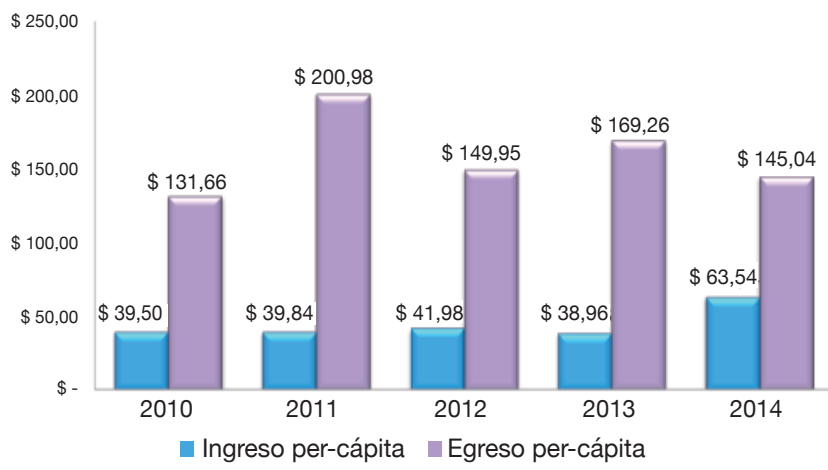

Fuente: Dirección Financiera, GAD Municipal de Patate

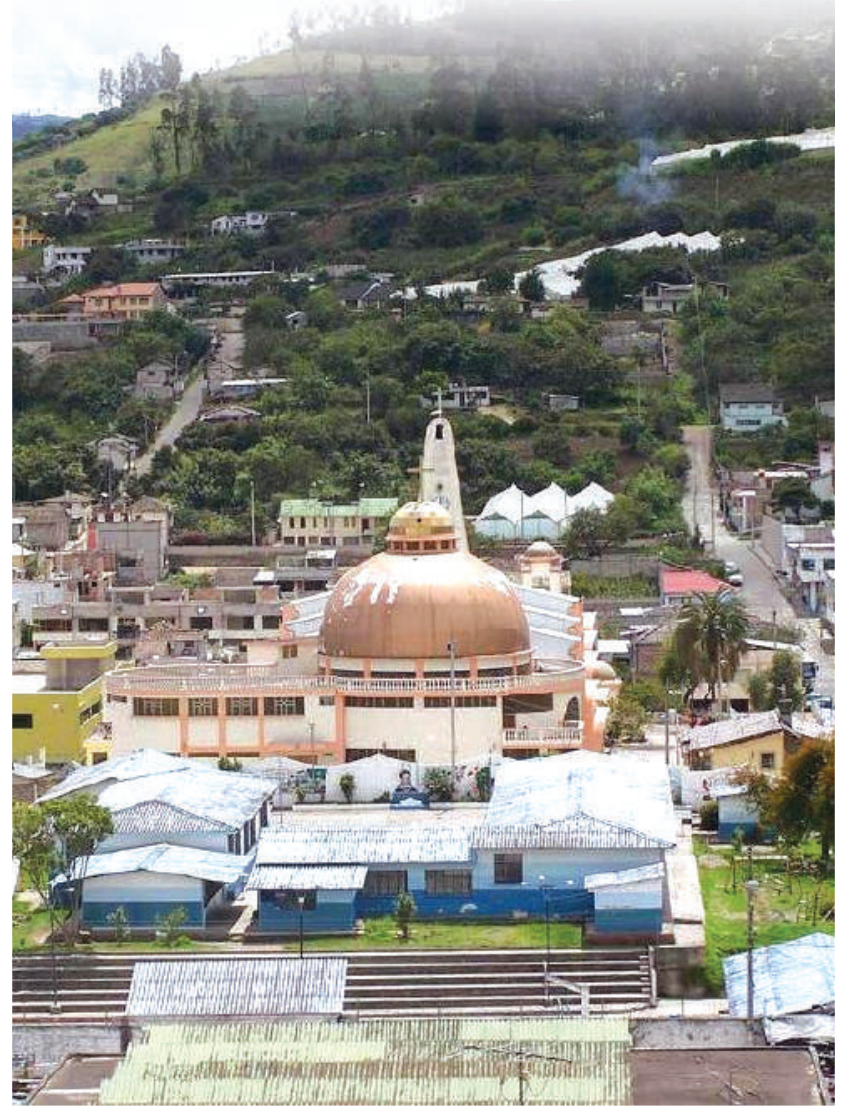

\section{Referencias:}

- Asamblea Nacional, Código Orgánico de Planificación y

Finanzas Públicas, 2010

- Gobierno Autónomo Descentralizado Municipal de Patate, Resumen de ingresos y gastos presupuestarios, Dirección Financiera, periodo $2010-2014$.

- Ministerio de Finanzas, Clasificador presupuestario de ingresos y gastos del sector público, Actualizado al 12 de junio de 2014.

\section{Elaboración:}

Econ. Juan Pablo Martínez Mesías, Mg

Econ. Tatiana Vayas Carrillo

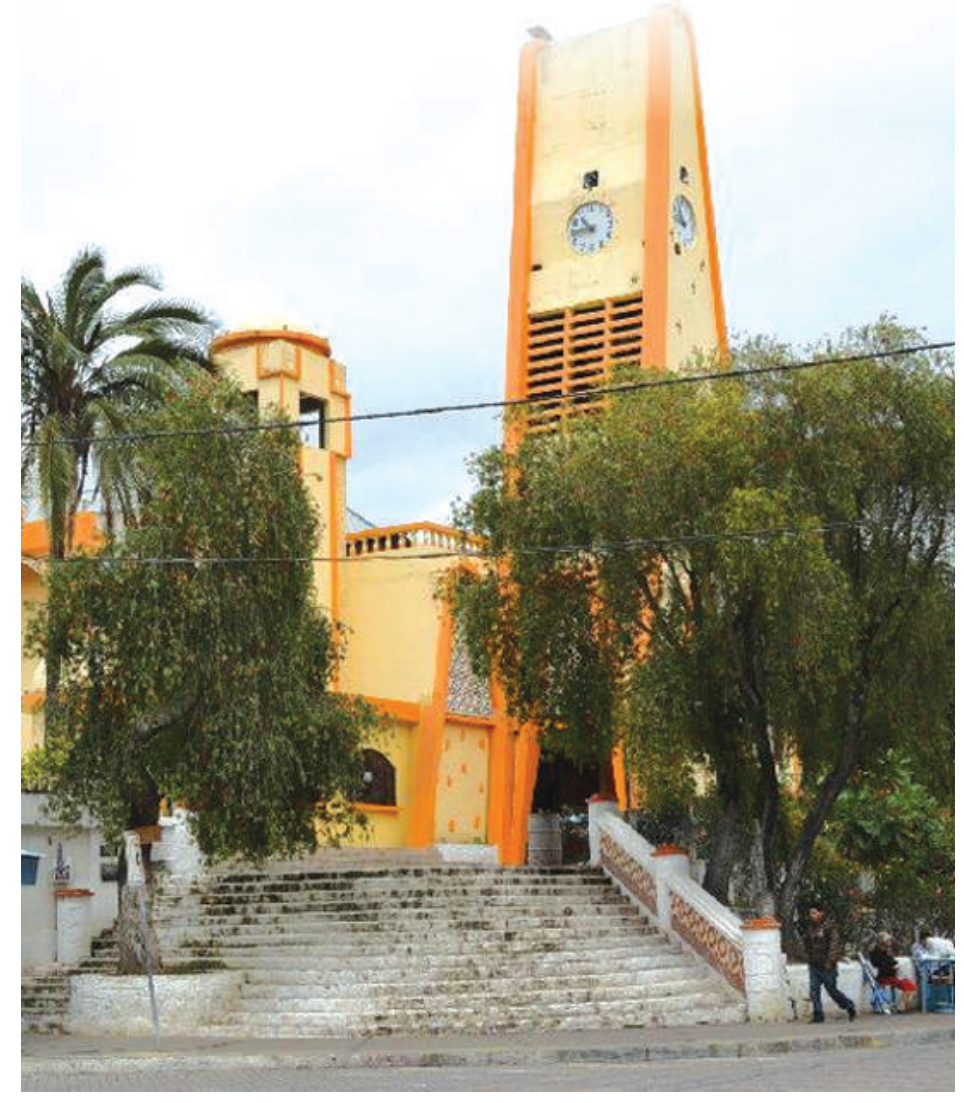

